\title{
Percepções de professores de Química sobre o trabalho em espaços de educação não formal e os desafios para incluir estudantes com deficiência nesses locais
}

\author{
Perceptions of Chemistry teachers about classes at non-formal \\ educational places and the challenges for include students with \\ disabilities in these places
}

\section{Percepciones de los profesores de Química sobre el trabajo en espacios de educación non-formal y los retos para incluir estudiantes con discapacidad en estos lugares}

\author{
Bruna Olívia da Silva Lopes 1 \\ https://orcid.org/0000-0002-4388-2686 \\ Vinícius Catão ${ }^{2}$ \\ https://orcid.org/0000-0003-459I-9275 \\ Regina Simplício Carvalho ${ }^{3}$ \\ https://orcid.org/0000-0002-0679-4070
}

\begin{abstract}
Resumo: Investigou-se neste trabalho a percepção de professores de Química sobre o potencial dos espaços não formais para favorecer o processo de ensino e aprendizagem dos conceitos químicos, tendo o foco nas questões educacionais relativas à inclusão. Nesta pesquisa qualitativa/exploratória entrevistou-se seis professores de Química em duas escolas públicas de Viçosa (MG), abordando o trabalho nestes espaços não formais e as possibilidades que eles apresentam para incluir diferentes estudantes. As entrevistas semiestruturadas foram transcritas e analisadas com base na Análise de Conteúdo de Bardin. Os resultados apontaram que, embora haja dificuldades logísticas, os professores avaliaram que nestes espaços os estudantes interagem mais com novos saberes e com os colegas, contextualizando a Química. Concluiu-se que os dois Museus analisados não estavam preparados para atender os estudantes público-alvo da Educação Especial devido a falta de acessibilidade física e linguística, além da escassez de tecnologias assistivas para acessar as informaç̧̃es dos acervos em exposição.

Palavras-chave: Educação Química. Inclusão. Espaços não formais de educação.
\end{abstract}

\footnotetext{
I Mestre em Mestrado profissional em Química pela Universidade Federal de Viçosa (UFV). Professora na Rede Estadual de Ensino de Minas Gerais. E-mail: bruna.lopees05@gmail.com.

2 Doutor em Educação pela Universidade Federal de Minas Gerais (UFMG). Professor no Departamento de Química da Universidade Federal de Viçosa (UFV). E-mail: vcasouza@ufv.br.

3 Doutora em Química pela Universidade Federal de Minas Gerais (UFMG). Professora no Departamento de Química da Universidade Federal de Viçosa (UFV). E-mail: resicar@ufv.br.
} 


\begin{abstract}
In this paper, we investigated the perception of Chemistry teachers about the potential of non-formal places to favor the learning process, including students with disabilities related to inclusive educational perspective. In the research, characterized as qualitative/exploratory approach, six in-service Chemistry teachers from two public High Schools at Viçosa (Brazil) were interviewed about their classes in these places and the possibilities that its present to include different students. The semi-structured interviews were transcribed and analyzed based on Bardin's Content Analysis. The results showed that, although there are logistical difficulties to visit Museums, the teachers evaluated that these are places where students interact more with scientific knowledges and other colleagues. It was concluded that the two Museums visited are not yet prepared to attend students with disabilities, due to the lack of accessibility physical and linguistic (Braille and Brazilian Sign Language), and assistive technologies to access information about the collections on display.
\end{abstract}

Keywords: Chemistry Education. Inclusion. Non-formal places.

Resumen: Este trabajo investigó la percepción de docentes de Química sobre el potencial de los espacios no formales para favorecer el proceso de enseñanza y aprendizaje de conceptos químicos, enfocándose la inclusión. En esta investigación cualitativa/exploratoria, se entrevistó seis profesores de Química de dos escuelas públicas de Viçosa (Brasil), abordando el trabajo en estos espacios no formales y las posibilidades que presentan para incluir diferentes estudiantes. Las entrevistas semiestructuradas fueran transcritas y analizadas con base en el Análisis de contenido de Bardin. Los resultados mostraron que, además las dificultades logísticas, los docentes evaluaron que en estos espacios los estudiantes interactúan mejor con los conocimientos científicos y sus compañeros, contextualizando la Química. Se concluyó que los dos Museos analizados no estaban preparados para atender al público de la Educación Especial debido a la falta de accesibilidad física y lingüística, además de la falta de tecnologías asistenciales para acceder informaciones de las colecciones.

Palabras-clave: Educación química. Inclusión. Espacios no formales de educación.

\title{
Introdução
}

Ainda são grandes os desafios enfrentados no espaço escolar e na educação brasileira considerando-se que a nossa sociedade passa por constantes mudanças na busca por atribuir sentido ao conhecimento, que não tem mais seu lócus principal na escola. Segundo Parreira e Filho (2010), a escola, como espaço de aprendizagem, lida com inúmeras transformações, não sendo mais o único local que permitirá ao indivíduo acessar diferentes saberes. De acordo com Arantes, Ghanem e Trilla (2008), os espaços de educação não formal, com os seus variados recursos para favorecer a prática educativa, não deveriam ser compreendidos como opostos ou alternativos à escola. Eles deveriam ser entendidos como complementares a ela. Além disso, é importante considerar a educação como um fenômeno complexo, multiforme, disperso, heterogêneo, permanente e quase onipresente, que pode acontecer de diversas formas e em diversos lugares (KRASILCHIK; MARANDINO, 2007).

Assim, um dos desafios da contemporaneidade tem sido caracterizar a educação não formal, uma vez que usualmente ela é definida por sua negatividade, ou seja, pelo que ela não representa (GOHN, 20I4). O conceito adotado por Gohn (20l4, p. 40) considera a "educação não formal como um processo sociopolítico, cultural e pedagógico de formação para a cidadania". Nesse sentido, entende-se o sociopolítico como sendo a formação do indivíduo para interagir e conviver em sociedade, atuando de forma consciente e assumindo valores éticos. $\mathrm{O}$ aprendizado adquirido e 
compartilhado neste tipo de educação não é espontâneo, porque a sua produção se relaciona a processos que têm propostas definidas e intencionalidades. Assim, pode-se considerar que a educação não formal pode contribuir para transformar um indivíduo em um cidadão crítico e participativo, pois oportuniza um processo de conscientização do seu contexto sócio-histórico-cultural (PARREIRA; FILHO, 20I0), permitindo que o indivíduo seja capaz de atuar no meio ao qual está inserido, modificando-o com as práticas sociais. Desta forma, as diferentes abordagens educativas podem contribuir para que alguns dos objetivos formativos no Ensino Médio sejam alcançados, considerando que o artigo 35 da Lei de Diretrizes e Bases da Educação Nacional - LDB (Lei n 9.394/1996) estabelece que:

Art. 35. O ensino médio, etapa final da educação básica, com duração mínima de três anos, terá como finalidades: I - a consolidação e o aprofundamento dos conhecimentos adquiridos no ensino fundamental, possibilitando o prosseguimento de estudos; II - a preparação básica para o trabalho e a cidadania do educando, para continuar aprendendo, de modo a ser capaz de se adaptar com flexibilidade a novas condições de ocupação ou aperfeiçoamento posteriores; III - o aprimoramento do educando como pessoa humana, incluindo a formação ética e o desenvolvimento da autonomia intelectual e do pensamento crítico; IV - a compreensão dos fundamentos científico-tecnológicos dos processos produtivos, relacionando a teoria com a prática, no ensino de cada disciplina (BRASIL, 1996, Art. 35).

Considerando o disposto na LDB e a necessidade de aprimorar as práticas educativas, de modo a obter maior envolvimento dos estudantes no processo formativo, despertar a curiosidade e o espírito investigativo, o presente trabalho analisa como os espaços não formais de educação podem favorecer o processo de ensino e aprendizagem da Química, na busca pela formação de cidadãos críticos e reflexivos, capazes de intervirem em seu meio social. Essa análise será feita considerando a necessidade de contemplar uma educação para todos, sem restrição daqueles que apresentam algum tipo de necessidade educacional diferenciada (NED), grupo este denominado na legislação como público-alvo da Educação Especial - PAEE (BRASIL, 2008). Destacamos ainda o disposto na Política Nacional da Educação Especial: Equitativa, Inclusiva e com aprendizado ao longo da vida (BRASIL, 2020), que busca assegurar as oportunidades de desenvolvimento e aprendizado a todos estudantes, considerando que a educação não acontece apenas na escola. Ela perpassa os diferentes espaços formais e não formais, em um processo contínuo que pode ser planejado ou casual. Assim, analisamos a percepção de um grupo de professores de Química sobre o trabalho nos espaços não formais e como é a acessibilidade destes locais quando se considera o processo de acolhimento e inclusão dos estudantes com deficiência visual (DV). Cabe destacar que consideramos, de acordo como o Glossário da Educação Escolar (INEP, 2020), que: 
Deficiência visual - Consiste na perda total ou parcial da visão, congênita ou adquirida, em nível variável. Pode ser classificada como cegueira ou baixa visão.

Cegueira - Perda total da função visual ou pouquíssima capacidade de enxergar. Nesse caso, devem ser disponibilizados ao estudante a aprendizagem e o uso do Sistema Braille de leitura e escrita, o mais precocemente possível, bem como materiais didáticos acessíveis, recursos tecnológicos e equipamentos adequados ao processo de comunicação (INEP, 2020, p. 7).

Nesse sentido, é importante esclarecer que a motivação para este trabalho se relaciona à experiência vivenciada por uma das autoras que, como professora de Química no Ensino Médio,

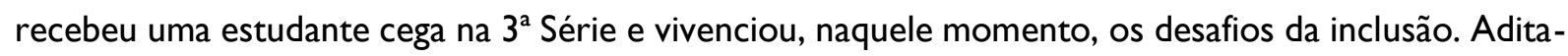
se a isso o fato de que o número de alunos com NED tem crescido nos últimos anos e estes estão ainda sem o devido apoio educacional nas salas de aula. De acordo com os dados do Censo da Educação Básica para o período de 2015-2019:

O número de matrículas da educação especial chegou a 142.098 em 2019, um aumento de $28 \%$ em relação a 2015 . O maior número de matrículas está nos anos iniciais do ensino fundamental, que concentra $38 \%$ das matrículas da educação especial. Quando avaliada a diferença no número de matrículas entre 2015 e 2019 por etapa de ensino, percebe-se que as matrículas de ensino médio cresceram 194,2\% (INEP, 2019, p. 38).

Diante do cenário de expressivo aumento no atendimento dos alunos com NED, constata-se na prática que um dos principais problemas da inclusão se relaciona à falta de preparo dos profissionais da educação para atender as demandas adaptativas, considerando que vivemos em uma sociedade que nos condiciona a lidar com a igualdade e não com as diferenças (BENITE et al., 2009). Estes aspectos formativos negligenciados na inclusão repercutem diretamente nas abordagens metodológicas. Além disso, é importante considerarmos outras questões que extrapolam esse âmbito formativo, tal como os aspectos arquitetônicos e programáticos nos espaços educacionais, como destacou Sassaki (2009).

\section{Inclusão dos estudantes com deficiência visual em espaços não formais de educação}

O sistema educacional brasileiro passa por algumas mudanças, tendo em vista as demandas voltadas à inclusão escolar (BENITE et al., 2009) e aos recentes dispositivos legais relacionados à essa questão. Dentre eles, destacam-se a Lei Brasileira de Inclusão da Pessoa com Deficiência (Estatuto da Pessoa com Deficiência) (BRASIL, 2015) e a Lei $n^{\circ}$ 13.409, de 28 de dezembro de 2016, que alterou e ampliou a já existente lei de cotas, reservando vagas para pessoas com deficiência em cursos técnicos de nível médio e superior nas instituições federais de ensino (BRASIL, 2016). Nesse sentido, levando em consideração a contemporaneidade das leis, é fato que atualmente as instituições de ensino têm encontrado dificuldades para implementar a inclusão de alunos com NED. Além disso, tanto as estruturas físicas quanto pedagógicas das escolas ainda são insuficientes para atender às muitas 
demandas formativas no campo da inclusão. Esses problemas não atingem somente a Educação Básica. Eles são verificados inclusive nas universidades, onde o despreparo no atendimento às NED foi apontado por Comarú e Coutinho (2013) como sendo o principal responsável pelo número ainda pequeno de alunos com deficiência no Ensino Superior. Ainda hoje, esta situação parece não ter mudado muito, mesmo com as recentes legislações. Há muito o que avançar ainda.

Segundo Aragão (2012, p. 37), "os alunos com deficiência podem alcançar o mesmo nível de desenvolvimento que aquele atingido pelos outros alunos". Entretanto, ele fará isso de uma maneira diferente, a partir de caminhos adaptativos que serão definidos de acordo com as NED apresentadas por cada um, dependendo do tipo de deficiência e do ambiente ao qual estão inseridos. Isso pode ser verificado ao se tratar de alunos que apresentam deficiências sensoriais, como a cegueira. Para auxiliar o aluno com deficiência visual (DV), há o sistema de escrita Braille. Ainda de acordo com Aragão (2012), para que ocorra o desenvolvimento desses alunos, a escola deve desempenhar um papel primordial, criando possibilidades que proporcionem a construção coletiva do conhecimento junto a esses alunos. Dessa forma, é necessário que os professores repensem as atividades a serem desenvolvidas, principalmente aquelas realizadas com alunos que apresentam DV, buscando as devidas adaptações metodológicas para se ter um ensino que contemple a todos e atendam às NED presente em sala de aula. É importante que isso seja pensado inclusive quando se articula algum trabalho em espaços de educação não formal, que precisam, com a ajuda dos professores e profissionais capacitados da escola, implementar as adaptações necessárias para receber os estudantes com DV.

Nesse sentido, consideramos que a formação científica pode ser oportunizada pela utilização dos espaços não formais, pois avaliamos que estes favorecem o processo de ensino e aprendizagem, permitindo o desenvolvimento do pensamento crítico e reflexivo sobre a nossa relação com o mundo. Assim, diversas discussões e propostas sobre a inclusão escolar vêm permeando as instâncias educativas, uma vez que o ensino de Química não é voltado somente aos estudantes sem deficiência (BENITE et al., 2009). É necessário pensar em uma educação por meio das Ciências que seja acessível a todos, com ações democráticas e humanas, sem subjugar ou ser indiferente à condição do outro. Isso contempla a escolarização e a educação, sendo este último um processo mais amplo que abrange os diferentes espaços sociais, incluindo neles os não formais e o atendimento educacional especializado. De acordo com Santiago e Santos (20I5):

As atividades desenvolvidas no atendimento educacional especializado diferenciamse daquelas realizadas na sala de aula comum, não sendo substitutivas à escolarização, ou seja, esse atendimento complementa e/ou suplementa a formação dos estudantes com vistas à autonomia dentro e fora da escola (SANTIAGO; SANTOS, 20I5, p. 486). 
Nesse sentido, os espaços não formais de educação podem também favorecer o processo de ensino dos estudantes com NED, pois pode favorecer a construção do conhecimento e estimular a curiosidade. Nascimento, Sgarbi e Roldi (2014) e Amado, Cazaroto e Alencar (2012) apontam que o trabalho nos espaços não formais vem há algum tempo chamando atenção de educadores e pesquisadores de diversas áreas da educação, pois promovem atividades que vão além da divulgação científica, favorecendo a conexão entre teoria e prática, cotidiano e aprendizagem, sujeito e objeto de conhecimento. Isso, por si só, já demonstra a importância desses espaços para favorecer o processo formativo dos estudantes na Educação Básica, devendo assim buscar atender a diversidade do público que poderá ter acesso a esses locais.

\section{Aspectos metodológicos da pesquisa}

O presente estudo apresenta uma abordagem qualitativa, de caráter exploratório. Entendemos que o principal objetivo da Pesquisa Exploratória é proporcionar maior familiaridade com o objeto investigado. Muitas vezes, o pesquisador não possui conhecimentos suficientes para formular adequadamente um problema de pesquisa ou elaborar com precisão uma hipótese. Nesse caso, é necessário "desencadear um processo de investigação que identifique a natureza do fenômeno e aponte as características essenciais das variáveis que se quer estudar" (KÖCHE, 1997, p. 126). Além disso, ressaltamos também que a abordagem exploratória se justificada pela falta de estudos científicos sobre o fenômeno apreendido.

Assim, o planejamento da Pesquisa Exploratória se torna flexível e pode se alinhar a uma Pesquisa Bibliográfica, Documental, Estudos de Caso, dentre outros. As estratégias de investigação possíveis de serem utilizadas na Pesquisa Exploratória são: formulários, questionários, entrevistas, registros escritos, além da leitura e documentação de diferentes materiais. Nesta pesquisa, a estratégia de investigação utilizada foi a entrevista semiestruturada com professores da Educação Básica. A coleta dos dados foi realizada por meio destas entrevistas, nas quais buscou-se obter dados comparáveis entre os diversos sujeitos entrevistados. Neste tipo de entrevista, o entrevistador encoraja o sujeito a falar sobre uma determinada área de interesse. Em seguida, explora-a mais profundamente, retomando os tópicos e os temas iniciados pelos participantes (BOGDAN; BIKLEN, 1994).

De acordo com Aragão (20I2, p. 48), "a utilização de entrevistas semiestruturadas possibilita a obtenção de informações dos participantes da pesquisa de maneira autêntica, o roteiro é flexível e o entrevistador pode fazer as alterações necessárias durante a entrevista”. Ibiapina (2008, p. 77) acrescenta ainda que a entrevista "[...] apresenta diferentes condições que favorecem a produção do discurso e o dialogismo, possibilitando análises mais aprofundadas e substanciais do objeto em estudo". 
Assim, a fase inicial da pesquisa envolveu a realização de uma entrevista piloto com uma professora que se voluntariou a contribuir com esta etapa do trabalho. $O$ objetivo dessa entrevista inicial foi garantir que o roteiro proposto estivesse adequado ao público-alvo. De acordo com Nicolaci-da-Costa (2007):

\begin{abstract}
Um primeiro rascunho de roteiro deverá ser elaborado a partir dessas conversas. Esse rascunho, por sua vez, deverá ser testado em outras conversas, que, por já terem uma estrutura provisória, são chamadas de entrevistas-piloto. Muito provavelmente, a partir dessas entrevistas, o roteiro sofrerá sucessivas modificações e será submetido a novos testes. Quando tudo fluir bem (este é o melhor critério), o roteiro estará pronto (NICOLACI-DA-COSTA, 2007, p. 69).
\end{abstract}

Logo, essa parte foi fundamental para fazer as alterações necessárias e elaborar o roteiro final da entrevista que foi realizada com os seis professores participantes. A entrevista piloto foi realizada com uma professora da Educação Básica que era vinculada ao Programa de Mestrado Profissional em Química em Rede Nacional (PROFQUI). A escolha dessa professora para avaliar e calibrar o questionário inicialmente proposto se justifica pela facilidade de acesso a ela nas aulas presenciais do curso que aconteciam aos sábados e a disponibilidade da mesma $O$ roteiro inicial da entrevista semiestruturada foi composto por onze questões. Após esta primeira entrevista, retirou-se uma questão do roteiro piloto e acrescentou-se três novas. Essa alteração foi necessária para sondar os professores sobre os principais desafios que estes encontravam ao lidar com alunos que apresentam algum tipo de NED ao trabalhar em espaços fora da escola e até mesmo em suas salas de aula.

$\mathrm{Na}$ etapa seguinte de coleta dos dados, as entrevistas foram realizadas com um grupo de seis professores de Química do Ensino Médio de duas escolas públicas na cidade de Viçosa (MG). A escolha destas escolas foi feita considerando a proximidade de ambas e a facilidade de acesso aos professores. Ou seja, utilizou-se o critério da conveniência. Dos seis professores entrevistados, quatro eram da Escola I e dois da Escola 2. As entrevistas foram gravadas em áudio e transcritas para posterior análise. $\mathrm{Na}$ entrevista, os professores foram identificados por códigos alfa numéricos do tipo $\mathrm{Px}$, em que $\mathrm{x}$ representa um número de ordem, atribuído aleatoriamente, garantindo assim o anonimato e assegurando que nenhum constrangimento seria gerado a eles, conforme constava no Termo de Consentimento Livre e Esclarecido assinado por todos. Além disso, todas as falas foram marcadas em itálico para que, dessa forma, fossem distinguidas das demais ideias apresentadas no decorrer do texto. Sobre a análise dos dados, eles foram submetidos ao processo de Análise de Conteúdo, seguindo os pressupostos de Laurence Bardin (20II), que se caracteriza por:

Um conjunto de instrumentos metodológicos cada vez mais sutis em constante aperfeiçoamento, que se aplicam a "discursos" (conteúdos e continentes) extremamente diversificados. $\bigcirc$ fator comum destas técnicas múltiplas e 
multiplicadas - desde o cálculo de frequências que fornece dados cifrados, até à extração de estruturas traduzíveis em modelos - é uma hermenêutica controlada, baseada na dedução: a inferência (BARDIN, 20Il, p.I5).

Ainda de acordo com essa autora, o que serve de informação "na análise qualitativa é a presença ou ausência de uma dada característica de conteúdo ou de um conjunto de características num determinado fragmento de mensagem que é tomado em consideração" (BARDIN, 20II, p. 27, destaque nosso). Dessa forma, a análise foi dividida em três diferentes fases, sendo que na primeira foi feita uma pré-análise das entrevistas, caracterizada como a etapa de organização dos dados propriamente dito. Na segunda fase foi realizada uma exploração mais aprofundada do material e na última fez-se o tratamento dos dados, a inferência e a interpretação. Informamos, ainda, que este estudo foi submetido e aprovado pelo Comitê de Ética em Pesquisa com Seres Humanos da Universidade Federal de Viçosa, tendo o seu parecer consubstanciado disponibilizado em 06 de setembro de 2018 , sob o número 2.878 .46 I e CAAE 9335 I7I8.4.0000.5I53.

\section{Resultados e discussão}

Após a seleção das escolas participantes, foram contatados os professores das respectivas instituições para apresentar a proposta do trabalho e agendar as entrevistas. Para iniciar, será descrito na Tabela I o perfil formativo (graduação) e o tempo de docência de cada professor entrevistado. Isso permitirá conhecer, de forma geral, o grupo investigado neste trabalho, buscando assim respaldar algumas das inferências que serão feitas na análise das entrevistas.

Tabela I. Descrição do perfil formativo, em nível de graduação, e do tempo de docência dos professores entrevistados por Escola.

\begin{tabular}{|c|c|l|c|}
\hline Escola & Código do professor & $\begin{array}{l}\text { Descrição do perfil formativo dos } \\
\text { professores entrevistados }\end{array}$ & $\begin{array}{c}\text { Experiência } \\
\text { profissional como } \\
\text { professor }\end{array}$ \\
\hline \multirow{2}{*}{ EI } & PI & $\begin{array}{l}\text { Licenciado em Química pelo Centro } \\
\text { Universitário de Caratinga }\end{array}$ & 20 anos \\
\cline { 2 - 4 } & P2 & $\begin{array}{l}\text { Bacharel em Ciência e Tecnologia de } \\
\text { Laticínios pela UFV }\end{array}$ & 20 anos \\
\cline { 2 - 4 } & P3 & $\begin{array}{l}\text { Licenciado em Química pela Universidade } \\
\text { Federal de Santa Maria }\end{array}$ & 31 anos \\
\hline E2 & P5 & $\begin{array}{l}\text { Graduado em Medicina Veterinária pela } \\
\text { Universidade Federal de Viçosa e } \\
\text { posteriormente cursou a Licenciatura } \\
\text { Química à distância. }\end{array}$ & 29 anos \\
\hline
\end{tabular}

Olhar de professor, Ponta Grossa, v. 24, p. I-24, e-18397.090, 202 I.

Disponível em <https://revistas2.uepg.br/index.php/olhardeprofessor> 


\begin{tabular}{|l|l|l|c|}
\hline & P6 & $\begin{array}{l}\text { Licenciado em Química pela Universidade } \\
\text { Federal de Viçosa }\end{array}$ & I4 anos \\
\hline
\end{tabular}

Fonte: Autores, 202I.

Buscou-se verificar inicialmente se os professores tinham o hábito de desenvolver atividades em espaços não formais de educação e com que frequência essas atividades aconteciam. Dos seis professores entrevistados, apenas P6 afirmou não ter o hábito de realizar atividades em tais espaços. De acordo com esse professor, as atividades diferenciadas que realizava eram relacionadas aos projetos da escola que, normalmente, constavam no calendário escolar. Outro fator dificultador apontado por P6 foi a reposição de dias letivos devido à greve e paralisações, fazendo com que não sobrasse tempo para a realização de atividades fora do ambiente escolar. Isso pode ser confirmado por meio da transcrição da fala a seguir:

P6: O que a gente faz mais é dentro dos projetos mesmo que a gente tenta desenvolver algumas atividades diferentes, até porque tem projetos demais. Então, acaba que o tempo que sobra às vezes a diretora quer que a gente fique mais dentro da sala de aula. Ainda mais por essa questão da greve então, a gente não está tendo tanto tempo pra estar desenvolvendo atividades fora da escola.

Os outros professores relataram que têm o hábito de desenvolver aulas em espaços não formais, como podemos observar nas falas dos professores P3 e P4, enquanto o professor P5 teve essa experiência ao trabalhar como monitor na Escola I, como podemos verificar nas transcrições a seguir:

P3: Olha só... essas práticas aconteciam duas vezes ao ano, mas ultimamente eu não sei o que está acontecendo, não sei se é com o tempo, com a disponibilidade que se reduziu muito. [...] lembrei agora da Estação de Tratamento de Água [...] da Sala Mendeleev [Museu de Ciências/Química localizado no campus Viçosa da UFV], no Museu de Mineralogia. Tudo isso se faz pelo menos uma vez por ano.

P4: Normalmente eu procuro utilizar principalmente levando os alunos na Estação de Tratamento de água, uma visita que a gente costuma fazer aqui na Universidade. A gente costuma levar os meninos na Sala Mendeleev [...] e a estação de tratamento é visita anual que a gente sempre faz. No caso do Museu de Solos a gente faz, mas esporadicamente... não tem certa regularidade.

P5: Eu já realizei quando eu estava trabalhando como monitor de escolas que eu trabalhei, tive a experiência de trabalhar na Escola I aqui, a gente tinha essa abertura de levar os alunos para espaços não formais de ensino. Mas como professor ainda não tive essa oportunidade.

Ao serem questionados sobre o interesse e participação dos estudantes nas atividades realizadas em espaços não formais, os professores relataram que eles se mostram participativos, sobretudo porque as visitas normalmente despertam o interesse e a curiosidade e isso contribui para uma melhor compreensão do conteúdo, como podemos verificar nas falas transcritas de PI e P3. 
Percepções de alguns professores de química sobre o trabalho em espaços de educação não formal...

PI: Ah sim, mostram. Porque acaba que a gente tem uma conversa antes, tem uma parte assim mais motivadora e também a gente acaba pontuando também né, porque não tem como negar. Eles esperam isso né, a pontuação. É um motivador, é um gatilho, digamos assim. Mas eles gostam, participam.

P3: Muito interessados, muito participativos... teve um estudante de Química que era nosso monitor e ele fez o trabalho de conclusão de curso dele baseado nesses espaços não formais que foram as visitas do Museu de Mineralogia. É uma coisa mais descontraída e acho que são bem disciplinados, na hora da visita eles se mostram bem interessados e se ele estiver interessado, consequentemente ele aprende, participa e consegue associar as coisas.

É importante destacar aqui que PI afirmou que prepara os estudantes para a realização das atividades fora da Escola. Isso é considerado algo muito relevante no processo formativo, pois permite que os estudantes compreendam o vínculo da atividade com as discussões fomentadas em sala de aula. Acreditamos que tal ação docente favorece um maior comprometimento dos estudantes com a atividade e permite que ela seja retomada em sala de aula para, posteriormente, integrar o processo avaliativo. Nesse sentido, concordamos com Krasilchik e Marandino (2007) quando destacaram que a preparação, acompanhamento, retomada e avaliação das atividades realizadas nos espaços não formais de educação são essenciais para dar sentido às visitas como parte do processo educativo. Sobretudo quando reconhecemos que a Escola tem a responsabilidade de trazer conhecimentos básicos sobre Ciências, mas que sozinha é incapaz de disponibilizar todas as informações científicas necessárias à compreensão do mundo a nossa volta. Assim, entendemos que é fundamental desenvolver ações conjuntas e incentivar a busca pelo conhecimento científico em diferentes espaços, de modo a promover uma educação por meio das Ciências que atendam o seu propósito de formar cidadãos críticos e reflexivos frente a sociedade que os cercam. Seguindo a discussão, P4 destacou que a motivação e interesse dos estudantes pelas aulas em espaços não formais se justificava pelo fato de serem atividades diferentes daquelas que normalmente acontecem na Escola, não fazendo parte da rotina deles, como pode ser verificado na fala transcrita a seguir:

P4: Então, o aluno gosta, comenta, aquilo rende comentário o ano todo, mas exatamente porque foi uma coisa diferente. Eu acho que se isso fosse também uma rotina, ir de novo sair para visitar não sei o que, ir de novo para ir ao museu tal, sabe? Então eu reconheço que os alunos gostam e que os alunos se sentem motivados, mas eu acho que não alimento a ilusão de que, "ah então vou fazer isso toda semana para tê-los ali sempre motivados" sabe? Eu não alimento essa ilusão não.

Esse maior envolvimento dos estudantes em atividades realizadas nos espaços não formais pode ser explicado pelas múltiplas possibilidades de explorar assuntos diversificados, tendo o contato direto com o ambiente e uma melhor compreensão dos fenômenos estudados. Dessa forma, as aulas 
desenvolvidas em espaços não-formais podem ampliar as possibilidades de aprendizagem dos estudantes, proporcionando-lhes um maior engajamento com os conteúdos científicos. De acordo com Rocha e Terán (201I, p. 3), isso só é possível devido às características inerentes aos espaços nãoformais, que despertam emoções e servem como motivadores para a aprendizagem. Segundo Back et al. (2017), ao explorar ambientes não formais, pode-se articular a contextualização, aplicação e associação de conhecimentos já aprendidos em sala de aula com informações novas, diminuindo a abstração do conteúdo. Vale ressaltar, ainda, que para favorecer a aprendizagem, as práticas desenvolvidas fora de sala de aula devem estar em diálogo com os objetivos curriculares, possibilitando a atribuição de sentido ao que é estudado. Isso foi verificado na fala dos professores quando questionados se eles acreditavam que estes espaços traziam algum benefício ao processo de ensino e aprendizagem dos estudantes. P5 relatou que eles podem favorecer $\circ$ processo de ensino e aprendizagem, mas para isso é importante que o estudante esteja ciente dos propósitos formativos ao visitar esses locais. Caso contrário, ele poderá considerar a visita apenas como um momento de lazer e não de aprendizado, conforme destacado a seguir:

P5: Então, eu acho que sim, que a utilização dos espaços não formais pode trazer benefícios de extrema necessidade para auxiliar nesses processos de ensino e aprendizagem, porém o aluno tem que estar ciente que esse espaço é para isso, porque se ele não tiver essa ideia, ele vai chegar lá e não vai poder aproveitar o mínimo que for o local em que a gente está levando ele. Ele vai achar que é só lazer e nem sempre é pelo lazer que ele vai, mas a gente vai com o intuito de dar uma aula. Tem que ter essa seriedade também por parte do aluno para que o processo de ensino e aprendizagem aconteça. É basicamente isso.

A fala apresentada por P5 é corroborada pelo trabalho de Rocha e Terán (2011), quando afirmam que se o professor não organizar/preparar a visita, estabelecendo os objetivos que deverão ser atingidos, ela pode acabar se transformando em uma atividade somente de recreação, perdendose a oportunidade para aprender algo relacionado à Química e as Ciências em geral. Dessa forma, para que a aprendizagem nos espaços não formais seja favorecida, é essencial que haja um bom planejamento, pois ao se realizar uma visita sem a devida preparação dos estudantes e sem a sistematização do conhecimento que eles possam adquirir a partir de suas observações durante a visita, corre-se o risco de a atividade se transformar exclusivamente em um momento de entretenimento. Isso foi apontado também por PI, que acredita ainda que esses locais podem favorecer a aprendizagem pelo fato dos estudantes se encontrarem em um ambiente mais agradável e sem as formalidades do ambiente escolar. Ele acredita que a oportunidade de observar as etapas envolvidas no tratamento de água, por exemplo, proporciona uma outra vivência aos estudantes, diferente de assistir aulas com slides abordando esse mesmo assunto: 
Percepções de alguns professores de química sobre o trabalho em espaços de educação não formal...

PI: Com certeza, por exemplo, quando eu falo de tratamento de água, se eu ficar só na sala mostrando slide e indo para o quadro, eles não vão ter o mesmo conhecimento de irem lá né, e observar as etapas, de ter uma pessoa de lá falando com eles, então é outra vivência, é outra coisa. [...] E eles têm a oportunidade lá de estar mais à vontade, não está dentro de uma sala de aula "enfileiradinho", ele está lá num ambiente mais agradável.

PI relatou ainda que o aprendizado adquirido nesses espaços vai além da educação formal. A experiência vivida pelos estudantes também pode ajudá-los no âmbito da socialização, aprendendo a ouvir, respeitar e reconhecer os diferentes saberes:

\begin{abstract}
PI: No dia que a gente foi no sítio de dona Terezinha e do seu Jésus, um lugar muito simples com pessoas muito simples, mas que eles ouviram com muito respeito sabe, e respeitaram que é um outro saber, reconheceram que essas pessoas são sábias e que eles têm muito o que ensinar. Então eu achei bonito, no final eles abraçaram, agradeceram. $E$ têm muitos meninos hoje em dia que não têm experiência de nada. Às vezes é criado em apartamento, não têm vivência de nada. O pai leva, a mãe busca, o pai e a mãe estão levando e buscando nos espaços, não é um menino que pega um ônibus, que conhece as pessoas. E muitas vezes é sala e computador, né. Só em celular, só internet, então eles estão ficando cada vez mais introspectivos, sabe. Aqueles jovens que não sabem aproximar de uma pessoa, não sabe manter uma conversa, então cada vez mais a escola está preocupada com isso também.
\end{abstract}

Já P3 comentou que esses espaços despertam um interesse maior dos alunos, permitindo que eles consigam associar o conteúdo estudado em sala de aula com as explicações trazidas nesses locais. Isso acaba aguçando a curiosidade e o desejo por aprender coisas diferentes, conforme mencionado pelo referido professor: "[...] desperta um interesse maior e eles conseguem associar e acaba que até desperta a vontade de estudar outras coisas, habilidades diferentes". Nesse sentido, um dos principais objetivos a serem alcançados nesses espaços não formais seria a conscientização sobre "o papel e a importância da ciência na sociedade, proporcionando experiências educativas para que os usuários compreendam princípios científicos e tecnológicos, despertando um interesse pela ciência e pela tecnologia" (JACOBUCCl, 2008, p. 64). Os espaços não-formais são importantes para ampliar o conhecimento científico dos estudantes, uma vez que podem estimular a curiosidade e suprir alguma carência da escola, dentre elas a falta de laboratórios de Ciências, informática e também de recursos audiovisuais e materiais, que são ferramentas usadas para favorecer o processo de ensino e aprendizagem. Além disso, Back et al. (2017) apontam que os benefícios que podem ser alcançados pelos estudantes e professores é o enriquecimento dos conteúdos desenvolvidos em sala de aula. $\mathrm{Na}$ sequência, solicitou-se aos professores que descrevessem quais as principais dificuldades enfrentadas para utilizar os espaços não formais. Os resultados podem ser verificados no Gráfico I a seguir. 
Gráfico I: Principais dificuldades encontradas pelos docentes.

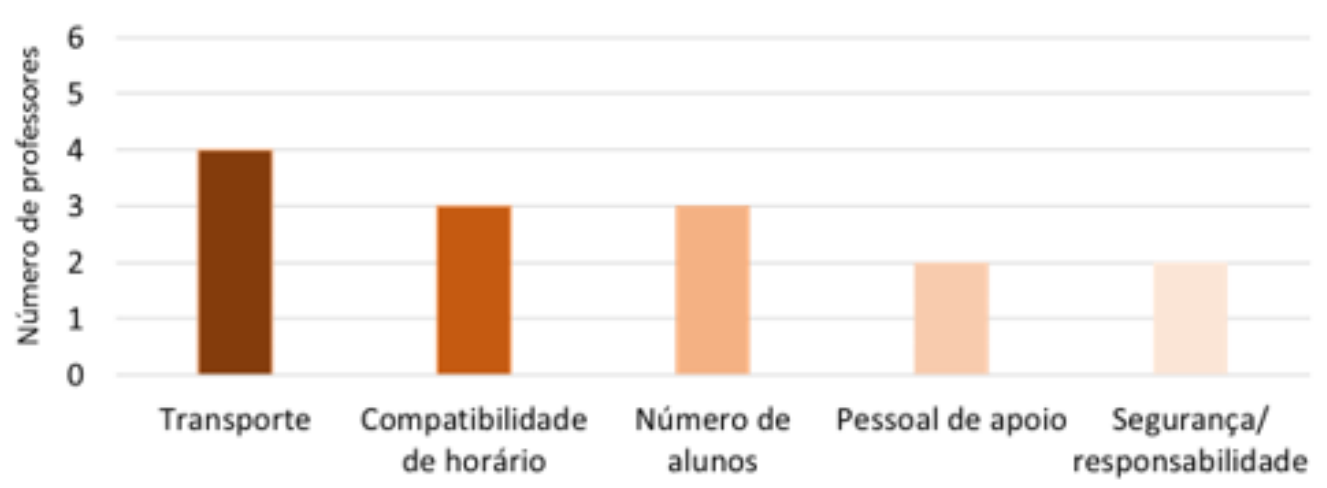

Fonte: Autores, 2021.

No Gráfico I, verifica-se que dos seis professores entrevistados, quatro deles apontaram como principal dificuldade a falta de transporte (PI, P3, P4 e P6). Isso pode ser verificado nas falas de PI, P3 e P4 destacadas a seguir:

PI: O transporte é mais complicado se você for para um lugar mais longe, é complicado o transporte [...]. Tem essa questão, você tem que ter alguém te assessorando, tem a questão do transporte e a responsabilidade com esses meninos, é complicado, eles são menores, você saiu com eles, você é responsável, é um peso muito grande.

P3: [...] ou até a questão de transportes. Se às vezes aqui dentro da universidade já fica complicado, mas, eu acho que é uma questão de se organizar, planejar e dar muito certo. E o professor tem que estar disponível, por exemplo, quando se vai nesses espaços não formais, por exemplo, vai de manhã á tarde você sabe que tem que estar em sala de aula e volta de novo são cento e sessenta alunos, quatro turmas, você tem que estar disposto pelo menos umas oito vezes.

P4: [...] A gente até gostaria de visitar outros locais, talvez, pelo número de alunos são cento e sessenta alunos então quer dizer, levar todos os alunos implicaria aí quatro ônibus. Então, a logística envolvida é mais complicada. Talvez a gente acabe ficando um pouco reduzido nesses locais, restritos a cidade e como a cidade tem alguns locais interessantes, mas uma dificuldade também, não vou dizer uma impossibilidade porque acho que é um pouco forte, mas, assim a dificuldade de acesso a outros locais para expandir esses locais de visitação.

De uma forma geral, quando se discute sobre a saída da Escola, o fator transporte é preponderante destacado por grande parte dos professores no nosso país, pois a maioria das escolas geralmente não dispõem de transporte para realizar tais atividades (XAVIER; LUZ, 20I5). Muitas vezes os ônibus disponíveis são utilizados apenas para transportar os estudantes das áreas rurais para a cidade, onde se encontram as escolas. Estes transportes não podem ser usados para visitas ou outras atividades educacionais. Para que o uso deles seja possível, muitas vezes os professores ou diretores 
contam com a parceria da Prefeitura ou dos próprios estudantes, juntamente com suas famílias, para assumirem o transporte. Três professores (PI, P4 e P5) apontaram dificuldades para a compatibilidade de horário, pois a matriz curricular dos estudantes envolve as mais diversas atividades e projetos, 0 que muitas vezes não deixa espaço para realizar as visitas, como podemos verificar nas falas de P4 e P5:

P4: Num primeiro momento dessas visitas a gente tem que marcar extra turno ou contra turno, então. Se os alunos têm aula de manhã, a gente tem que marcar a visita à tarde. Ou se eles têm aula á tarde, tem que marcar a visita de manhã. Então, aqui no colégio, particularmente, que os alunos têm muitas atividades, às vezes esse evento que a gente marca ele está competindo, às vezes, com outras atividades que os alunos têm que fazer. É até um obstáculo, às vezes, de conseguir uma data na agenda do Colégio e dos alunos para que a gente consiga fazer essa visita.

P5: O mais difícil foi a escola achar um período que a escola disponibilizasse esses alunos pra gente. Eu acredito que a gente que tem uma vivência em escola pública, eu acabo vendo que na escola pública a gente tem a possibilidade de chamar o aluno novamente para escola em outros momentos muito mais fácil do que na escola particular, porque eles estão sempre ali "prendendo" o aluno em atividades extracurriculares e acaba que não possibilita a gente isso. E essas atividades são sempre voltadas para o ensino formal. Então acaba que não possibilita, tendo outras aulas a tarde e tal.

Esta dificuldade encontrada pode ser justificada pela falta da inserção de tais práticas no currículo da escola, não sendo dada prioridade às atividades dessa natureza na formação dos estudantes. De acordo com Parreira e Filho (2010), a educação não deve se restringir aos processos de ensino e aprendizagem que acontecem apenas nos espaços formais, mas devem ser compreendidas dentro de uma perspectiva formativa mais ampla. Nesse sentido, as Orientações Curriculares para o Ensino Médio (BRASIL, 2006) sugerem o desenvolvimento de práticas fora do espaço escolar, apontando a abordagem do meio social como algo motivador para os estudantes. Pensando nisso, avaliamos que o currículo escolar não deve ser implementado apenas no espaço escolar. Ele deve ser elaborado de forma que contemple os locais nos quais os alunos possam ter uma reflexão mais ampla sobre o conhecimento científico. Os espaços não formais de ensino são locais onde não há a mesma intencionalidade e formalidade da Escola, mas são locais importantes para favorecer a construção de novos conhecimentos articulados a uma prática contextual com o foco na formação cidadã.

Outra dificuldade citada pelos professores foi o número de alunos, uma vez que seria necessário mobilizar vários transportes ou várias visitas para atender a todos os grupos. Também citaram a falta de um profissional que possa acompanhá-los nessas visitas e, por fim, alguns sentem receio em sair com os estudantes, pois é uma responsabilidade muito grande, uma vez que serão responsáveis pela segurança deles e quaisquer eventualidades que possa ocorrer, conforme destacado nas falas transcritas a seguir: 
PI: [...] A questão de você ter outras pessoas junto nessa atividade, considerando que são adolescentes, que situações podem acontecer que você precisa de ter alguém ali também te assessorando nessas atividades é importante.

P3: E o professor tem que estar disponível, por exemplo, quando se vai nesses espaços não formais, por exemplo, vai de manhã, á tarde você sabe que tem que estar em sala de aula e volta de novo. São cento e sessenta alunos, quatro turmas, você tem que estar disposto pelo menos umas oito vezes.

P6: A questão da logística, questão de segurança. Porque você fica responsável pelos meninos, então os pais ficam meio receosos e aqui tem muito aluno especial. Os meninos foram para o Inhotim [referência a um dos mais expoentes museus de arte contemporânea do Brasil e considerado o maior a céu aberto do mundo, localizado no município de Brumadinho-MG, mas aqui há facilidade porque tem professor de apoio, o que ajuda bastante. Mas dependendo da quantidade, do número de alunos também, eu acho que fica mais difícil de você conseguir atender a todos [...].

$\mathrm{Na}$ sequência da entrevista, averiguou-se se os professores já haviam trabalhado com estudantes que apresentavam alguma deficiência. Em caso afirmativo, foi solicitado que eles descrevessem quais foram as deficiências. Todos os professores relataram que tiveram alunos que apresentaram alguma deficiência, em maior ou menor grau, com destaque para alunos cegos, surdos, pessoas com transtorno do espectro autista (TEA) e esquizofrênicos, como mostrado nas falas de alguns professores:

PI: Já tive uma estudante que ela era cega, há muitos anos lá em Ipatinga [MG], no Colégio $X$, mas essa menina ela tinha uma maquininha $[\ldots]$.

P4: Eu já tive alguns alunos deficientes visuais, mas, assim, que usava óculos que precisava ampliar a prova. Mas aparentemente durante a aula nunca exigiram uma atenção especial. E em Ponte Nova uma vez foi no Colégio que eu trabalhava lá teve uma aluna que estava com um processo de perda de visão. Ela estava começando a desenvolver uma doença e aquilo vinha piorando. Teve alguma degeneração de nervo, algo desse tipo, mas foi durante o processo. Então, quer dizer, uma coisa que configurou assim já recebeu um aluno e aí foi coisa de um ano, dois. Teve um que foi um ano no Colégio, depois um ano no cursinho e essa menina foi dois anos no Colégio.

P5: Olha só, até o ano passado eu não tive essa experiência não, mas assim que eu comecei a trabalhar nessa escola, eu tive vários alunos surdos, alunos com deficiências motoras, alunos com deficiência visual, alunos com problemas congênitos, Down, com problemas de nascimento, no parto e isso acabou prejudicando alguma coisa na formação.

P6: Aqui a gente tem muitos alunos especiais. Têm alunos com deficiência visual, auditiva, autismo tem vários casos, esquizofrenia.

De acordo com as respostas anteriores, questionou-se aos professores sobre o uso de estratégias diferenciadas para lidar com estes estudantes. Entre as estratégias mencionadas, destacouse $o$ uso de avaliações adaptadas, modelos concretos e avaliação oral. Verificou-se na fala de alguns 
professores a dificuldade que eles encontraram para lidar com tais estudantes, sendo que alguns deles procuravam formas de contemplá-los em suas aulas, enquanto outros adotavam basicamente as mesmas estratégias de ensino usadas com os demais alunos ou recorriam ao professor de apoio. Além disso, verificou-se que as estratégias utilizadas eram pouco variadas. Isso pode ser justificado, muitas vezes, pela falta de preparo dos professores ao receberem esses alunos em suas salas de aula, conforme apontaram os trabalhos de Benite et al. (2009) e Sassaki (2009). Nesse sentido, as falas a seguir destacam algumas das ideias aqui abordadas.

P5: Eu tento fazer uma avaliação diferenciada nos moldes do que eu avaliei os outros alunos. Então se eu dei um gráfico de mudança de estados físicos, eu tento fazer uma questão de mudança de estados físicos de forma que ele consiga interpretar dentro da deficiência dele, é uma coisa que no início é mais difícil porque a gente não conhece $\circ$ aluno, então não sabe qual vai ser a dificuldade dele. [...] $\bigcirc$ outro aluno cego, por outro lado, ele não tem isso. Então avaliar ele é uma coisa bem mais difícil. É mais uma avaliação boca a boca, perguntar uma coisa, ter um momento com ele.

P6: Na verdade acaba que a gente volta mais para o professor de apoio do que para o aluno, porque eu não consigo, às vezes, atingir diretamente o aluno. Por exemplo, tem um aluno que tem autismo, às vezes eu não sei lidar com o jeito. [...] se eu te falar assim a gente usa alguma estratégia diferenciada, não, o que ajuda a gente muito são os professores de apoio. Porque eu mesmo já tentei algumas vezes e eu não consigo. Assim, dependendo diretamente com o aluno eu não consigo às vezes entender o que $\circ$ aluno está perguntando, a questão da comunicação é um pouco complicada.

O número de estudantes com NED em Minas Gerais e em todo Brasil tem crescido, de acordo com dados do INEP (2019), mas como verificado anteriormente na fala dos professores entrevistados, constata-se na prática que o grande problema para incluir estes estudantes é o despreparo para recebêlos e lidar com suas demandas inclusivas, como mencionado por Benite et al. (2009). Além da falta de profissionais capacitados, é fato que as instituições de ensino têm encontrado dificuldades na implementação da proposta de inclusão dos estudantes com NED, sobretudo quando se verifica a inadequação das salas de aulas, dos recursos e materiais didáticos que são insuficientes, associado à falta de profissionais capacitados. Além disso, tanto as estruturas físicas, quanto as pedagógicas das escolas, ainda são muito insuficientes, como destacaram Sassaki (2009) e Comarú e Coutinho (2013). Isso reflete uma realidade difícil quando se vislumbra o principal propósito da inclusão, que é a busca pela equiparação de oportunidades por meio de métodos adaptativos nas escolas e universidades. Quando muitos ingressam, não conseguem permanecer devido à falta de condições para as devidas adaptações que se fazem necessárias para avançar no processo formativo, como pode-se observar nos estudos realizados por Castro e Almeida (20I4), ao afirmarem que uma educação superior que preze pela presença de todos os alunos na universidade necessita de investimentos em ações, em materiais 
adequados, em qualificação docente, em adequação arquitetônica, e principalmente, em ações que combatam atitudes inadequadas e preconceituosas.

Dessa forma, para que ocorra o pleno desenvolvimento desses estudantes, a instituição deverá desempenhar um papel primordial, criando e construindo possibilidades que proporcionem $\circ$ desenvolvimento desses alunos. Assim, é necessário que os professores repensem as atividades realizadas, principalmente aquelas feitas com estudantes que apresentam DV, pois o trabalho desenvolvido na escola será diferenciado pelas ações desses profissionais. Nesse sentido, Benite et al. (2009) destacam a importância de os indivíduos terem acesso ao conhecimento científico para exercerem a cidadania de forma efetiva em todas as esferas da sociedade, tendo eles NED ou não. Esse ensino pode ser oportunizado pela utilização dos espaços não formais e de diferentes metodologias de ensino que tenham o potencial para favorecer o processo de ensino e aprendizagem, permitindo a formação de cidadãos atuantes e autônomos.

Para finalizar, a última questão da entrevista procurou averiguar se os professores acham que os espaços não formais estão adaptados para receberem os estudantes com algum tipo de deficiência. Alguns professores, ao responder à questão, falaram dos espaços em geral. Outros citaram problemas de espaços que já haviam visitado. PI, por exemplo, destacou a falta de profissionais especializados para receber estudantes com deficiência e sobre a acessibilidade de cadeirantes nesses espaços:

PI: [...] $\circ$ que eu acho é que o maior desafio seria capacitar pessoas para receber esses alunos, que é uma coisa que nós não recebemos quando a gente tem $o$ aluno. [...] então eles podem ter contato, mas eu não me recordo de coisas em Braille, de escrita em Braille, eu não me recordo mesmo, fui lá [Museu de Ciências da Terra Alexis Dorofeef, localizado no campus Viçosa da UFV] já tem uns três anos, então eu não me recordo, mas eu sei que há possibilidade de levar eles e ter contato com o material e notar a diferença tátil e eu acho que é possível sim, levar eles lá. Tem que ter todo um acompanhamento, eu não vi se tem acessibilidade para eles entrarem, como é que fica essa facilidade, cadeirante, não tem rampa, outras acessibilidades eu já não sei.

P5 acredita que a falta de acessibilidade é encontrada em todo Brasil e muitos locais não dispõe de uma estrutura adequada, como podemos verificar em sua fala:

P5: De jeito nenhum, acho que como no Brasil todo, calçada não tem, acho que é uma característica não é da UFV, é do Brasil. [...] Lá na ETA [Estação de Tratamento de Água, localizado no campus Viçosa da UFV], principalmente, eu não conseguiria levar um cadeirante lá, uma pessoa com deficiência visual, não sei como faria, porque não é pensado, isso não é pensado, aí não tem nenhum planejamento.

De acordo com Tojal (20I5), os públicos com deficiência têm tido presença cada vez maior nos Museus e isso foi devido ao longo processo de abertura dessas instituições que eram espaços mais restritos e elitizados. Numa nova perspectiva de mudança de paradigma do Museu elitista para um 
Percepções de alguns professores de química sobre o trabalho em espaços de educação não formal...

Museu voltado a todos, é que ações dirigidas aos públicos com deficiência começaram a ganhar corpo. Isso vai ao encontro das ideias apresentadas por Schuindt (2019), ao afirmar que a diversificação do público nesses espaços tornou-se uma realidade eminente, principalmente pela necessidade de acolher esse visitante sem ignorar suas condições físicas, buscando incentivar práticas culturais inclusivas e impulsionar a inserção de pessoas que permaneceram segregadas desses espaços por tanto tempo. Acompanhando o conceito da nova museologia, Tojal (2015) destacou que:

Todos os processos de comunicação museológica deverão ter por objetivo garantir - pleno acesso ao patrimônio cultural, o que significa não somente permitir a entrada dos diferentes públicos, mas também possibilitar a esses visitantes estratégias de mediação que ofereçam plenas condições para que eles possam decodificar os conteúdos ali apresentados, e consequentemente, o direito de se reconhecerem como parte intrínseca desse patrimônio cultural, principalmente por parte daqueles que, por razões de vulnerabilidade social ou por deficiências sensoriais, físicas, emocionais e intelectuais fazem parte de grupos menos privilegiados (TOJAL, 2015, p. 197).

Podemos verificar nas falas apresentadas pelos autores supracitados que já existe alguma mudança em relação ao atendimento dos visitantes que possuem deficiência, mas na prática, ainda há muito a ser feito para que esses espaços possam realmente ser inclusivos. As falas apresentadas pelos professores P3 e P4 corroboram esse fato ao relatarem suas experiências em espaços não formais que já visitaram.

P3: Eu acho que não, assim a Sala Mendeleev o aluno chega, vamos dizer é um cadeirante ele vai pelo elevador, mas outro tipo de aluno... não sei não. [...] A Tabela Periódica é toda visual, agora para um cego, deficiente, você tem que ter alguma coisa para ele identificar. Ele vai ouvir, agora um surdo não vai comunicar.

P4: Não, a própria Estação de Tratamento de Água ela é pouco acessível até para aqueles que tem todas as funções motoras talvez já é um pouco difícil. Porque tem momento lá que a gente vai visitar o tanque de sedimentação você tem que subir uma escada lá que é difícil. Eu me lembro alunos lá que não subiu porque tinha alguma limitação de altura, não gosta de altura, então quer dizer, supostamente, ou até então eu não tive essa noção de deficiência, de limitação, mas esses locais a princípio, não foram projetados para isso a verdade é essa. [...] são coisas mais visuais e auditivas tem aquela salinha agora que discute a tabelinha, muito apertadinha se tivesse algum aluno cadeirante teria que ter alguma adaptação momentânea ali para ele poder entrar, ter acesso.

Ao analisar a fala do professor $\mathrm{P} 3$, infere-se que um estudante com DV ou surdez tem menos acesso às informações, não somente por sua limitação visual ou auditiva, mas pelas barreiras ain da presentes no sistema ao qual está inserido. É, portanto, possível constatar que essa proposta de acesso ao conhecimento não está disponível para todos os públicos. Os Museus em geral têm enfrentado muitas dificuldades, além da própria manutenção, para tornar seus espaços não somente acessíveis, 
mas também inclusivos. Dentre elas, verifica-se que a mais citada nas entrevistas foi a dificuldade em adequar suas visitas e exposições, garantindo que o visitante com deficiência possa usufruir de todo o espaço, compreendendo e apreciando o que se passa ali com o devido sentimento de pertencimento.

Outro fator que levou os professores a acreditarem que esses espaços não estão adaptados é a dificuldade de locomoção, seja por visitantes com deficiência motora ou visual. Segundo Schuindt (2019), as barreiras arquitetônicas, além de impedirem a livre circulação (acesso autônomo ao acervo em exposição), podem causar desconforto e constrangimentos. É importante que as relações de conhecimento articuladas no Museu perpassem pela percepção e apreensão do espaço, para que os visitantes possam conhecê-lo e interagir de forma autônoma e espontânea com a exposição. $O$ efeito que o lugar exerce sobre o indivíduo está relacionado à experiência que nele se pode ter. Dessa forma, para garantir a possibilidade e condição de alcance, percepção e entendimento do espaço, é necessário atender todo e qualquer tipo de necessidade diferenciada que o visitante tenha.

Além das dificuldades encontradas na utilização desses espaços em relação à acessibilidade citadas, P6 também disse não acreditar que os Museus estejam adaptados para receber os estudantes com deficiência, uma vez que nem as escolas estão: "Eu acredito que não, infelizmente não, até mesmo na escola tem algumas restrições" (P6). A fala apresentada por P6 reflete a realidade vivida pelos estudantes com algum tipo de NED ao se depararem com salas de aula ainda inadequadas, sem acesso aos recursos e materiais adaptados e com profissionais sem a devida preparação para atender suas demandas. As ideias apresentadas por Nascimento, Sgarbi e Roldi (2014) vão ao encontro daquelas apresentadas por Amado, Cazaroto e Alencar (2012), quando apontam que o uso dos espaços não formais vem há algum tempo chamando a atenção de educadores e pesquisadores de diversas áreas da educação, pois promovem atividades que vão além da divulgação científica, favorecendo a conexão entre teoria e prática, cotidiano e aprendizagem, sujeito e objeto de conhecimento (AMADO; CAZAROTO; ALENCAR, 2012). Dessa forma, esses espaços podem trazer grandes benefícios para os alunos, mas, infelizmente, o que vemos na prática é que muitos deles ainda não estão totalmente adaptados para receber os estudantes com deficiência e atender às suas especificidades.

\section{Conclusões e implicações do trabalho para o ensino de Ciências/Química}

Ao investigar as principais dificuldades encontradas pelos/as professores/as de Química do Ensino Médio na utilização dos diferentes espaços não formais de educação, verificamos que os maiores obstáculos estão na falta de transporte, na incompatibilidade de horários com outras atividades, no número excessivo de alunos, na falta de pessoal de apoio e também na segurança e na responsabilidade ao sair com esses alunos para espaços fora da escola. De uma forma geral, a falta de transporte foi 
Percepções de alguns professores de química sobre o trabalho em espaços de educação não formal...

fator preponderante, uma vez que a maioria das redes de ensino público não dispõem do suporte logístico para realizar visitas a esses espaços.

Verificou-se nos relatos dos professores que os espaços não formais de educação podem trazer benefícios ao processo de ensino e aprendizagem da Química. Várias foram as justificativas apresentadas pelos professores ao citarem a importância e as potencialidades desses locais, destacando que eles podem favorecer a contextualização do conhecimento, permitindo o estabelecimento de relações com o conteúdo estudado em sala de aula. Também pode favorecer vivências no âmbito da socialização, em que os estudantes têm a oportunidade de aprender a ouvir, respeitar e reconhecer os diferentes saberes, além de despertar o interesse e a curiosidade por conhecimentos de outras áreas que se integram à Química. Mas vê-se a necessidade de que as práticas desenvolvidas fora de sala de aula estejam em diálogo com os objetivos curriculares propostos nos documentos norteadores da Educação Brasileira, possibilitando a atribuição de sentido ao conhecimento em estudo. Também é importante que o estudante esteja ciente dos propósitos formativos ao visitar esses locais, para que o aprendizado seja realmente significativo, de modo que a atividade não seja entendida apenas como um momento de lazer. Dessa forma, para que a aprendizagem nos espaços não formais seja alcançada, é essencial que haja um bom planejamento e preparo prévio. Caso contrário, corre-se o risco da atividade se transformar num momento de entretenimento, sendo pouco expressiva para o estudante quanto ao aspecto da construção do conhecimento cientíico.

Além disso, constatou-se que todos os professores entrevistados tiveram estudantes com algum tipo de deficiência, em maior ou menor grau, destacando-se cegos, surdos, TEA e esquizofrênicos. Entre as estratégias diferenciadas usadas por eles para lidar com os estudantes que apresentavam NED, destacou-se o uso de avaliações adaptadas e oral, além de modelos concretos e outros materiais didáticos. Verificou-se ainda que as estratégias utilizadas eram pouco variadas. Isso pode ser justificado pela falta de capacitação dos professores para receberem tais estudantes e atender suas diferentes demandas no campo educacional. Esta falta da capacitação perpassa inclusive a formação inicial dos professores Química, uma vez que na maioria das vezes, não contempla estas discussões. Temos ainda o desafio de articular ações efetivas que permitam uma efetiva equiparação de oportunidades, na busca por construir um projeto de Educação (científica) que seja realmente inclusivo.

Assim, espera-se que com este trabalho tenhamos catalisado algumas reflexões e discussões fecundas a respeito da inclusão dos estudantes com NED nos espaços não formais de educação, nas escolas e nas universidades. Desejamos que esta discussão ressoe e suscite novas inquietações e estudos futuros, visando fomentar trabalhos que possam aprimorar a formação docente e as práticas educativas, além de permitir adaptações que favoreçam a inclusão e o acolhimento da diversidade nos diferentes espaços educativos.

Olhar de professor, Ponta Grossa, v. 24, p. I-24, e-18397.090, 2021.

Disponível em <https://revistas2.uepg.br/index.php/olhardeprofessor> 
$\mathrm{Na}$ luta incessante por uma sociedade mais justa e com escolas, universidades e espaços educativos/culturais/artísticos que sejam efetivamente inclusivos, seguimos com esse propósito de fazer uma educação por meio das Ciências/Química que nos traga a possibilidade de abranger o maior número de pessoas possível. Estamos firmes neste propósito, pois ainda há muito para avançarmos!

\section{Referências}

AMADO, M. V.; CAZAROTO, R. B.; ALENCAR, I. C. C. Educação ambiental: legislação e considerações sobre sua prática em espaço não formal de ensino. In: LEITE, S. Q. M. Práticas experimentais investigativas em ensino de Ciências. Vitória, ES: Instituto Federal de Educação, Ciência e Tecnologia do Espírito Santo, 2012. p.47-54.

ARAGÃO, A. S. Ensino de Química para alunos cegos: desafios no ensino médio. 2012. Dissertação (Mestrado em Ciências Humanas) - Universidade Federal de São Carlos, São Carlos, 2012, I 22 f. Disponível em:

https://repositorio.ufscar.br/bitstream/handle/ufscar/3 I I I/4705.pdf?sequence= I \&isAllowed=y. Acesso em: 25 de maio de 2021 .

ARANTES, V. A.; GHANEM, E.; TRILLA, J. Educação formal e não formal: Pontos e Contrapontos. I ${ }^{\mathrm{a}}$ ed, São Paulo: Summus, 2008.

BARDIN, L. Análise de conteúdo. $3^{\mathrm{a}}$ reimpressão da I a ed. São Paulo: Edições 70, $20 \mathrm{II}$.

BENITE, A. M. C.; PEREIRA, L.; BENITE, C. R. M.; PROCOPIO, M. V. R.; FRIEDRICH, M. Formação de professores de ciências em rede social: uma perspectiva dialógica na educação inclusiva. Revista Brasileira de Pesquisa em Ensino de Ciências, v.9, n.3, pp. I-2I, 2009. Disponível em: https://periodicos.ufmg.br/index.php/rbpec/article/download/3997/256I//3/97. Acesso em: 02 de dezembro de 2021 .

BOGDAN, R.; BIKLEN, S. K. Investigação qualitativa em educação: uma introdução à teoria e aos métodos. Porto: Porto Editora, 1994.

BRASIL. Ministério da Educação. Lei de Diretrizes e Bases da Educação Nacional. Lei n. 9.394, 1996. Disponível em: http://www.planalto.gov.br/ccivil_03/leis/19394.htm. Acesso em: 02 de dezembro de 2021 .

BRASIL. Ministério da Educação. Secretaria de Educação Básica (SEB). Orientações Curriculares para o Ensino Médio: Ciências da natureza, matemática e suas tecnologias. Brasília: MEC/SEB, 2006. Disponível em: http://portal.mec.gov.br/seb/arquivos/pdf/book_volume_02_internet.pdf. Acesso em: 02 de dezembro de 2021.

BRASIL. Ministério da Educação. Secretaria de Educação Especial (SEESP). Política Nacional de Educação Especial na Perspectiva da Educação Inclusiva. Brasília: MEC/SEESP, 2008. Disponível em: http://portal.mec.gov.br/arquivos/pdf/politicaeducespecial.pdf. Acesso em: 02 de dezembro de 2021 . 
BRASIL. Lei 13.I 46. Dispõe sobre a Lei Brasileira de Inclusão da Pessoa com Deficiência (Estatuto da Pessoa com Deficiência). Diário Oficial da União. Brasília, 06 de julho de 2015. Disponível em: http://www.planalto.gov.br/ccivil_03/_ato20I5-20I8/20I5/lei/lI3I46.htm. Acesso em: 02 de dezembro de 2021 .

BRASIL. Lei 13.409. Altera a Lei $n^{\circ} 12.7$ II, de 29 de agosto de 20I2, e dispõe sobre a reserva de vagas para pessoas com deficiência nos cursos técnico de nível médio e superior das instituições federais de ensino. Diário Oficial da União. Brasília, 28 de dezembro de 2016. Disponível em: http://www.planalto.gov.br/ccivil_03/_ato2015-2018/20I6/lei/ll3409.htm. Acesso em: 02 de dezembro de 2021.

BRASIL. Decreto 10.502. Institui a Política Nacional de Educação Especial: Equitativa, Inclusiva e com Aprendizado ao Longo da Vida. Diário Oficial da União. Brasília, 30 de setembro de 2020. Disponível em: https://www.in.gov.br/en/web/dou/-/decreto-n-10.502-de-30-de-setembro-de-2020280529948. Acesso em: 02 de dezembro de 202I.

CASTRO, S. F.; ALMEIDA, M. A. Ingresso e Permanência de Alunos com Deficiência em Universidades Públicas Brasileiras. Revista Brasileira de Educação Especial, v. 20, n. 2, p. 179 194, abr./jun., 20I4. https://doi.org/I0.I590/SI4I3-653820I4000200003. Acesso em: 15 de dezembro de 2021 .

COMARÚ, M. W.; COUTINHO, C. M. L. M. Para que incluir? Uma discussão sobre educação de alunos com deficiências, políticas públicas e as pesquisas em ensino de Ciências. Atas do IX

Encontro Nacional de Pesquisa em Educação em Ciências - IX ENPEC, Águas de Lindóia, SP - 10 a 14 de novembro, 2013. Disponível em:

http://abrapecnet.org.br/atas_enpec/ixenpec/atas/resumos/R0I80-I.pdf. Acesso em: 02 de dezembro de 2021 .

GOHN, M. G. Educação não formal, Aprendizagens e Saberes em Processos Participativos.

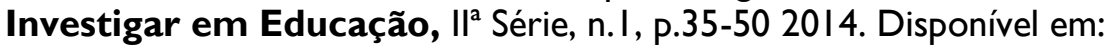

http://pages.ie.uminho.pt/inved/index.php/ie/article/view/4. Acesso em: 02 de dezembro de 2021 .

IBIAPINA, I. M. L. M. Pesquisa colaborativa: investigação, formação e produção de conhecimentos. Brasília, DF: Líber Livro, 2008.

INEP. Glossário da Educação Especial: Censo Escolar 2020. Brasília: Ministério da Educação, 2020. Disponível em:

https://download.inep.gov.br/educacao_basica/censo_escolar/caderno_de_instrucoes/Glossario_da_E ducacao_Especial_Censo_Escolar_2020.pdf. Acesso em: 02 de dezembro de 202I.

INEP. Resumo Técnico do Estado de Minas Gerais: Censo da Educação Básica 2019. BrasíliaDF: Ministério da Educação, 2019. Disponível em:

https://download.inep.gov.br/publicacoes/institucionais/estatisticas_e_indicadores/resumo_tecnico_d o_estado_de_minas_gerais_censo_da_educacao_basica_2019.pdf. Acesso em: 02 de dezembro de 2021 .

JACOBUCCI, D. F. C. Contribuições dos espaços não formais de educação para a formação da cultura científica. Em extensão, Uberlândia, v. 7, p.55-66, 2008. Disponível em: http://www.seer.ufu.br/index.php/revextensao/article/view/20390. Acesso em: 02 de dezembro de 2021. 
KÖCHE, J. C. Fundamentos de metodologia científica: Teoria da Ciência e iniciação à Pesquisa. $20^{\mathrm{a}}$ Edição (revista e atualizada). Petrópolis, RJ: Editora Vozes, 1997.

KRASILCHIK, M., MARANDINO, M. Ensino de Ciências e Cidadania. 2a Ed., São Paulo: Editora Moderna. 2007.

NASCIMENTO, F. N.; SGARBI, A. D.; ROLDI, K. A utilização de espaços educativos não formais na construção de conhecimentos - uma experiência com alunos do ensino fundamental. Revista da SBEnBio, n. 7, p. 2130-2139, outubro, 2014. Disponível em: https://renbio.org.br/index.php/sbenbio/issue/archive. Acesso em: 02 de dezembro de $202 \mathrm{I}$.

NICOLACI-DA-COSTA, A. M. O campo da pesquisa qualitativa e o Método de Explicitação do Discurso Subjacente (MEDS). Psicologia: Reflexão e Crítica, Porto Alegre, v. 20, n. I, p. 65-73, 2007. https://doi.org//0.1590/S0102-79722007000100009. Acesso em: I5 de dezembro de 202I.

BACK, D.; RADETZKE, F. S.; GÜNZEL, R. E.; WENZEL, J. S. Educação em Espaços não Formais no Ensino de Ciências. ANAIS [...] VII ENPEC - Encontro Nacional de Pesquisa em Educação em Ciências, Florianópolis. 2017. Disponível em: http://www.abrapecnet.org.br/enpec/xienpec/anais/resumos/RI066-I.pdf. Acesso em: 02 de dezembro de 2021.

PARREIRA, L. A.; FILHO, Pe M. J. A educação não formal: desafios de uma prática pedagógica. Serviço Social e Realidade, Franca, v. 19, n. I, p. 24I-268, 2010. Disponível em: https://periodicos.franca.unesp.br/index.php/SSR/issue/view/43. Acesso em: 02 de dezembro de 2021 .

ROCHA, S. C. B.; TERÁN, A. F. Contribuições dos espaços não-formais para o ensino de ciências. In: I Simpósio Internacional de Educação em Ciências na Amazônia - I SECAM, promovido pelo Programa de Pós-Graduação em Educação e Ensino de Ciências na Amazônia da Universidade do Estado do Amazonas-UEA, realizado em Manaus, 20 a 23 de setembro de 201 I. Disponível em: https://pos.uea.edu.br/data/area/evento/download/4-I.pdf. Acesso em: 02 de dezembro de 202I.

SANTIAGO, M. C.; SANTOS, M. P. Planejamento de Estratégias para o Processo de Inclusão: desafios em questão. Educação \& Realidade, Porto Alegre, v. 40, n. 2, p. 485-502, abr./jun. 2015. Disponível em: https://seer.ufrgs.br/educacaoerealidade/article/view/45248. Acesso em: 02 de dezembro de 2021.

SASSAKI, R. K. Inclusão: acessibilidade no lazer, trabalho e educação. Revista Nacional de Reabilitação - Reação, São Paulo, Ano XII, p.10-16, mar./abr. 2009. Disponível em: https://files.cercomp.ufg.br/weby/up/2 I I/o/SASSAKI_-_Acessibilidade.pdf? I 4732033 I9. Acesso em: 02 de dezembro de 2021 .

SCHUINDT, C. C. A educação inclusiva em espaços não formais: uma análise dos museus de ciências brasileiros. 2019. 243f. Dissertação (Mestrado em Educação em Ciências e em Matemática) Universidade Federal do Paraná, Curitiba, 2019. Disponível em:

https://pdfs.semanticscholar.org/2 Ifc/2f2ael ed97edd567f0fa9555 I I89d9555d2c.pdf. Acesso em: 25 de maio de 2021 . 
TOJAL, A. P. F. Política de acessibilidade comunicacional em museus: para quê e para quem? Museologia \& Interdisciplinaridade. Brasília, v. I V, n. 7, p. 190-202, out./nov. 2015. https://doi.org//0.265I2/museologia.v4i7.16779. Acesso em: I5 de dezembro de 202I.

XAVIER, D. A. L.; LUZ, P. C. S. Dificuldades enfrentadas pelos professores para realizar atividades de educação ambiental em espaços não formais. Revista Margens Interdisciplinar, v.9, n. 12, p. 2903II, 2015. http://dx.doi.org/I0.18542/rmi.v9i12.3077. Acesso em: I5 de dezembro de 202 I.

Recebido em: 14 de julho de 202 I

Versão corrigida recebida em: 25 de novembro de 2021 .

Aceito em: 25 de novembro de 2021 .

Publicado online em: 16 de dezembro de 2021. 